\title{
The Nimba Mountains in Guinea
}

\author{
Tetsuro Matsuzawa ${ }^{1,2,3}$
}

Published online: 8 December 2016

(C) Japan Monkey Centre and Springer Japan 2016

For some decades now, I have studied the wild chimpanzees of Bossou and Mount Nimba in Conakry, Guinea, West Africa, first travelling there for this research in February 1986. During my first survey, being a mountain climber, I took the opportunity to reach the peak of Mount Nimba (1752 m a.s.l.), summiting on 4 March 1986. This mountaintop had been trodden by many people, but this was certainly the first ascent by a Japanese person. From the top I was able to look down and see beautiful primary forest spreading out in all directions from the foot of the mountain.

My research target was the chimpanzees living in Bossou, a village located $10 \mathrm{~km}$ from the ridge of Mount Nimba. Mount Nimba, including Bossou, has been designated as a World Natural Heritage (WNH) site by the United Nations Educational, Scientific and Cultural Organization. Over the past three decades I have climbed to the summit of Mount Nimba many times by a variety of different routes. On 1 January 2016, I enjoyed climbing the mountain with my colleagues and local guides.

In this editorial, I want to introduce the reader to the beauty of Mount Nimba, the only WNH site in Guinea (Fig. 1). The Nimba Massif spreads north-northeast and south-southwest, and is located on the border of three countries. The north and eastern parts are in Guinea, the eastern part in Cote d'Ivoire, and the southern section in Liberia. Just as every Japanese person knows Mount Fuji

Tetsuro Matsuzawa

matsuzawa.tetsuro.8w@kyoto-u.ac.jp

Institute of Advanced Study, Kyoto University, Kyoto, Japan

2 Primate Research Institute, Kyoto University, Inuyama, Japan

3 Japan Monkey Centre, Inuyama, Japan
(3776 m) in Japan, everyone in West Africa knows Mount Nimba, the landmark of this region.

When climbing Mount Nimba this year, our route took us to the small village of Seringbara situated about $1 \mathrm{~h}$ walk from Bossou. Seringbara is at an altitude of $550 \mathrm{~m}$ a.s.l. and has a population of about 1200 . The villagers cultivate nearby land for rice, corn, manioc, banana, pineapple, papaya, etc. There are also many oil palms, which are an essential source of food to the local people, as every dish is cooked in the oil.

Leaving Seringbara village at 7:30 a.m., my colleagues and I climbed up to the ridge at $730 \mathrm{~m}$ a.s.l. that delimits the area of human habitation. Crops can be cultivated up to this ridge, but the area beyond is considered sacred, and nothing is allowed to be grown here. From the boundary ridge, we climbed down to the river at $595 \mathrm{~m}$ a.s.l. where one can enjoy fresh water. It is genuine primary forest here, in other words, a beautiful, montane tropical forest. No one lives in this area.

Since 1997, I have studied the wild chimpanzees in Seringbara, Nimba Massif, with Tatyana Humle, Kathelijne Koops and many volunteer students organized by Kathelijne who use chimpanzee trails to follow each group. The first guides I employed were Kassié Doré and Fromo Doré. The guides are the teachers of the forest, knowledgeable about many aspects of this area. Exploring the Seringbara, Nimba Massif, forest regularly for many years has allowed the guides and students to find the ideal route leading directly to the summit of Mount Nimba, and on this occasion we adopted this "Seringbara route" to the peak.

From the river, one climbs up through dark tropical forest. The word "jungle" may bring to mind a hot and humid climate, but in December and January the climate of the Nimba forest is very comfortable. The canopy provides shade from strong sunlight, and the temperature in the 
Fig. 1 Panoramic view of Mount Nimba from the West. The highest point is located on the peak to the farthest right. The mountainsides are green in the rainy season (photo by Naruki morimura)

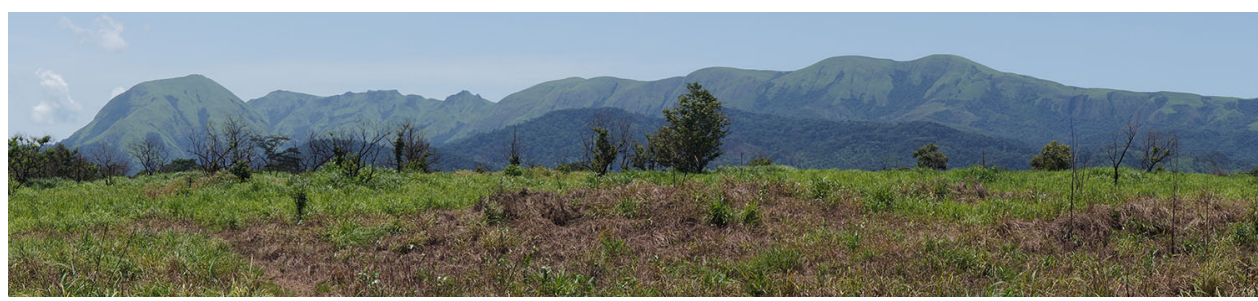

forest is maintained at about $24{ }^{\circ} \mathrm{C}$. You stop perspiring almost immediately in this dry season climate. In the forest, we found the fruit of Parinari spp., which is eaten by the chimpanzees. We also found chimpanzee feces on the trail, which contained seeds of the fruit of Landolphia spp.. Looking up, we saw nests made by the chimpanzees, about $10 \mathrm{~m}$ above the forest floor. I counted a maximum of 12 nests, and could imagine the chimpanzees lying on their backs in these nests, emitting soft vocalizations, at the end of the day.

At $1100 \mathrm{~m}$ a.s.l. the trees ended and the savanna began. The annual rainfall here is about $1500 \mathrm{~mm}$. There is sufficient water to support dense vegetation at the lower altitudes but not at the higher ones, thus trees grow lower down, but not in the upper regions of the massif. There tends to be savanna at higher altitudes, from where one can get a very clear view of Bossou to the west, far away. The upper part of the mountain starts from a steep rocky wall, and we had to climb up the rocks carefully, step by step. Extending from the top of the rock face is a narrow ridge with both sides dropping away very steeply. The ridge is very narrow, but the rocks there are stable and sound. We were not scared but actually enjoyed walking there in the breeze (Fig. 2).

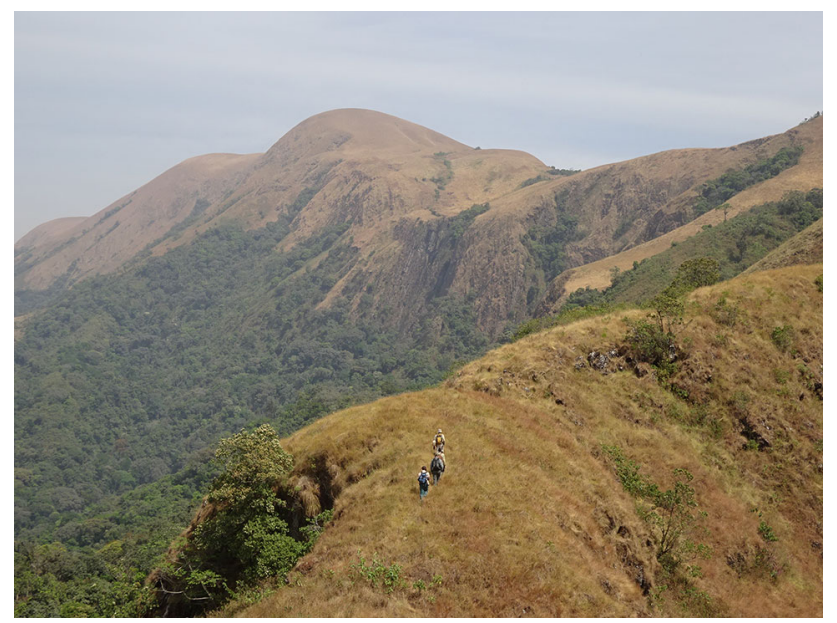

Fig. 2 Climbing the savanna, on the upper part of Mount Nimba, above the primary forest. My companions are walking ahead of me, and the summit is visible in the background. Also visible are the green bushes on the double ridge line that retain fresh water near the summit (31 December 2015; photo by Tetsuro Matsuzawa)
This narrow ridge leads to a small patch of forest, at 1310 m a.s.l., below Mount Nimba's main ridge. The ground here is flat and provides the ideal campsite, from where I could hear chimpanzee vocalizations from the primary forest below. My colleagues collected wood and prepared our meal of rice and tinned fish cooked in palm oil. I like campfires, and after eating our humble dinner we just sat and watched the fire for a long time.

We got up at 5 a.m. the next morning, when it was still dark. With the use of head lamps, we climbed up to the main ridge from which one can see the opposite side of the mountain, in Cote d'Ivoire. Looking back towards the south, we saw in the far distance the street lights of Lamco, a mining city in Liberia. We then continued climbing, up to the summit.

Suddenly, there was fresh water on our route, which was really amazing to see, on a mountain ridge so near the summit. This geographic feature is called a "double ridge line," i.e., a small valley within two ridges, resulting in a ridge-valley-ridge shape. There were small green bushes growing there, surrounded by the dry savanna of the ridge, which help retain the fresh water in the soil. I had never seen such a miracle in all my years in the mountains!

The stream, which formed a rocky depression much like a washbasin, was very narrow here, but wide enough to allow me to scoop up a handful of fresh water. I drank the water, washed my hands and face with it, then poured it onto my head, just like a shower. It felt chilly on my back, and greatly relieved my fatigue. I have never experienced such a feeling of refreshment, and spontaneously said out loud "Thank you, my God." This sacred water must surely bring one happiness and longevity.

At 7 a.m. on 1 January 2016, we reached the summit of Mount Nimba, which is very close to the location of the fresh water. Sunrise was not as we had expected: the sky was clear high up, but a little hazy near the horizon, so we could not see the sun. My colleagues and I enjoyed a $360^{\circ}$ view of the landscape from the top of the mountain, then slowly climbed down Mount Nimba to Seringbara, following the same route as earlier, starting out on the savanna, descending to the narrow ridge, then entering the primary forest with its high canopy. Finally, we returned to the village at 3 p.m.

There are 238 UNESCO WNH sites at present, and 669 Man and the Biosphere (MAB) sites. Yakushima Island in 


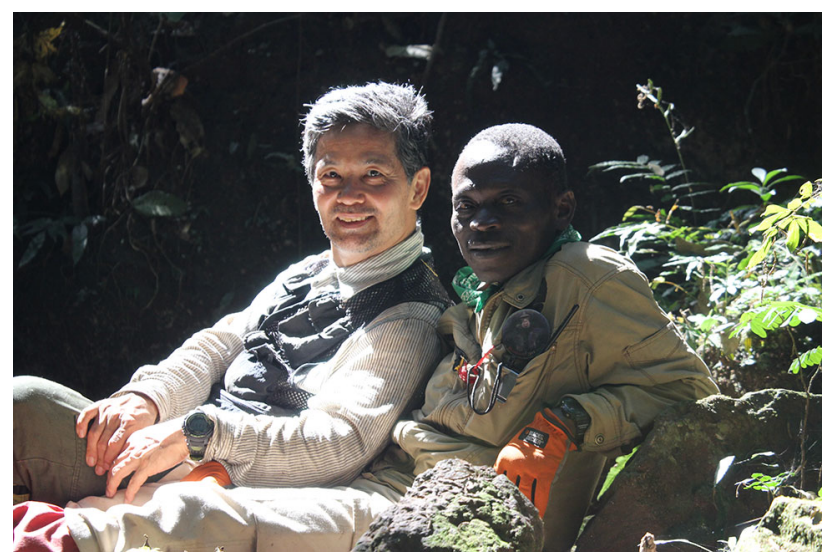

Fig. 3 Kassié Doré and Tetsuro Matsuzawa on the Nimba Massif on the reconnaissance expedition to Ziekepo Forest, located to the north of Seringbara, Mount Nimba (28 December 2011; photo by Jules Doré)

Japan is designated as both a WNH and MAB site. These sites are valued highly for their importance for conservation of the natural landscape, and are precious to people all around the world. However, unfortunately, Mount Nimba consists of rock rich in iron ore. The Liberian side of
Mount Nimba has already been excavated from the top, and mining activity has completely changed the shape of the Nimba Massif. The Seringbara side in Guinea is intact, but there is also mining activity in the northwestern part of the Nimba Massif. How can we stop the pressure of mining on the landscape? One plausible solution for this is ecotourism, whereby tourists could appreciate the beautiful natural environment here. Just as I have enjoyed the beauty of these mountains, many more people could appreciate the spectacular landscape of Mount Nimba, the treasure of people living in West Africa.

Recently, I have been thinking of the days I spent on Mount Nimba last January. However, I recognize that one important person of that place is no longer. My local assistant sent me an e-mail to let me know that my dear old friend, and guide, Kassié, passed away on 15 September 2016. He always accompanied me when I worked in the forests of Mount Nimba, and without his guidance I would have had no knowledge of the chimpanzees, trees or trails of this mountain. Kassié will never return, but I will continue to climb Mount Nimba in the coming years with memories of my old friend (Fig. 3). 